\title{
Erratum to: Obesity and Gastroesophageal Reflux: Quantifying the Association Between Body Mass Index, Esophageal Acid Exposure, and Lower Esophageal Sphincter Status in a Large Series of Patients with Reflux Symptoms
}

\author{
Shahin Ayazi • Jeffrey A. Hagen • Linda S. Chan • Steven R. DeMeester • \\ Molly W. Lin • Ali Ayazi • Jessica M. Leers • Arzu Oezcelik • Farzaneh Banki • \\ John C. Lipham • Tom R. DeMeester • Peter F. Crookes
}

Published online: 9 December 2009

(C) 2009 The Society for Surgery of the Alimentary Tract

Erratum to: J Gastrointest Surg

DOI 10.1007/s11605-009-0930-7

During conversion of the proof of this article to the final copy, a mistake occurred in the last two rows of Table 3. The correct values of the composite $\mathrm{pH}$ score [mean (SD)] are $41.5 \pm 48.0$ for defective LES and $20.7 \pm 25.4$ for normal LES.

The online version of the original article can be found at http://dx.doi. org/10.1007/s11605-009-0930-7.

S. Ayazi $\cdot$ J. A. Hagen ' L. S. Chan ' S. R. DeMeester

M. W. Lin · J. M. Leers - A. Oezcelik · F. Banki J. C. Lipham •

T. R. DeMeester $\cdot$ P. F. Crookes $(\square)$

Department of Surgery, Keck School of Medicine,

University of Southern California,

1510 San Pablo St, Ste 514,

Los Angeles, CA 90033, USA

e-mail: crookes@surgery.usc.edu

\section{A. Ayazi}

Department of Electrical Engineering, University of California,

Los Angeles, CA, USA 